\title{
EMOCIONES, CORPOREIDAD Y SOCIALIZACIÓN DE GÉNERO EN LA SUBJETIVACIÓN DE LA MASCULINIDAD DE JÓVENES CHILENOS: UNA APROXIMACIÓN INTERTEXTUAL DESDE EL MODELO DE MAPAS CORPORALE** EMOTIONS, EMBODIMENT AND GENDER SOCIALIZATION IN THE SUBJECTIVATION OF MASCULINITY OF YOUNGSTERS FROM CHILE: AN INTERTEXTUAL APPROACH FROM BODY MAPS MODEL \\ DOI: $10.22199 /$ S07187475.2014.0003.00005
}

Recibido: 20 de Octubre del 2014 | Aceptado: 02 de Diciembre del 2014

\author{
RICARDO ESPINOZA-TAPIA 1 ; JIMENA SILVA SEGOVIA2 \\ (UNIVERSIDAD CATÓLICA DEL NORTE, Antofagasta, Chile)
}

\begin{abstract}
RESUMEN
En el presente artículo se analiza el proceso de subjetivación de la masculinidad de un hombre joven del norte de Chile. El caso de "Hombre Constelación" se inserta en una investigación que buscó conocer cómo significan sus masculinidades jóvenes de 15 a 23 años socializados en un escenario cultural androcéntrico, patriarcal y heterosexista. La investigación es de tipo cualitativa y utiliza el modelo de mapas corporales. Este modelo se inscribe en el enfoque biográfico, utilizando análisis intertextual desde supuestos de la epistemología feminista para dar cuenta de la dimensión corporeizada de la socialización de género. Entre los hallazgos más relevantes se constata que el modelo de masculinidad de "Hombre Constelación" esta dado por una compensación entre el rechazo hacia una corporeidad disminuida y la exaltación de atributos propios de una masculinidad heteronormativa tales como la racionalidad y la virilidad, no existiendo así apertura hacia un modelo transformador en cuanto a las relaciones de género.
\end{abstract}

PALABRAS CLAVE: Corporeidad, jóvenes chilenos, socialización de género, subjetivación de la masculinidad.

\section{ABSTRACT}

In this article it's showed in depth a case about the process of subjectivation of masculinity of a young man in northern Chile. "Man Constellation" case is inserted in an investigation that sought to know how young men between 15 to 23 years old live their masculinities in an androcentric, patriarchal and heterosexist cultural scene. The research is qualitative and the methodological model used is body maps. This model is a biographical approach, it use intertextual analysis from feminist epistemology to account the embodied dimension of gender socialization. Among the most important findings is found that "Man Constellation" model of masculinity is given by a trade off between the rejection of a diminished corporeality and the exaltation of heteronormative masculinity attributes such as rationality and virility, there being no opening to a transformer model in terms of gender relations.

KEY WORDS: Embodiment, Chilean youngsters, gender socialization, subjectivation of masculinity.

\footnotetext{
* Este trabajo se ha realizado en el marco del programa de Doctorat en Psicologia Social de la Universitat Autònoma de Barcelona: "Persona i societat en el món contemporani". Asimismo, forma parte de la investigación "Significados Culturales del Cuerpo y el Autocuidado en jóvenes chilenos viviendo en una región minera". Esta investigación ha sido financiada por el Consejo Nacional de Ciencia y Tecnología (CONICYT), Chile

1. Académico Universidad Católica del Norte. Facultad de Humanidades. Escuela de Psicología. Avenida Angamos \#0610 Antofagasta, Chile. E-mail: respinoza@ucn.cl Teléfono: +56552355822.

2. Académica Universidad Católica del Norte Facultad de Humanidades. Escuela de Psicología. Avenida Angamos \#0610 Antofagasta, Chile. E-mail: jsilva@ucn.cl Teléfono: +5655 2355822.
} 


\section{INTRODUCCIÓN}

El campo en el que se sitúa la presente investigación corresponde al proceso de articulación y constitución de las identidades sexogenéricas al interior del sistema sexogénero (Rubin, 1975). Para Marcela Lagarde (1996) dicho sistema de relaciones sociales no solo define el estilo de las relaciones entre hombres y mujeres, sino también entre hombres.

Según su asignación de género, se establecen las posiciones que estos ocupan en dicho entramado, define los espacios en los que organiza a los sujetos, distribuye recursos para el ejercicio de poder, asigna atributos, especialización, normatividad, valores, jerarquías, privilegios y sanciones (Lagarde, 1996).

La masculinidad, por tanto, si es posible de ser definida brevemente, es al mismo tiempo la posición en las relaciones de género, las prácticas por las cuales los hombres y mujeres se comprometen con esa posición de género y los efectos de estas prácticas en la experiencia corporal, en la personalidad y en la cultura (Connell, 1987).

Al respecto, R.K. Connel $(1987 ; 1995)$ ha establecido una diferenciación entre lo que la autora denomina como "masculinidad hegemónica" y "las masculinidades marginadas", entendiéndolas más que tipologías de carácter inmutable, como configuraciones de prácticas generadas en situaciones particulares y en una estructura cambiante de relaciones.

Una característica central de este anclaje identitario al que denominaremos como "masculinidad hegemónica" es la heterosexualidad, mediante la sexualidad ejercida hacia el sexo opuesto como un hecho natural (Rubin, 1975; Kaufman 1985; Connell, 1987; Badinter, 1993; Gilmore, 1994; Lagarde, 1996; Lamas, 1996; Kimmel
1998; Llamas, 1998; Valdés y Olavarría, 1998; Olavarría y Parrini, 2000).

La denominada "masculinidad
hegemónica", asociada a la heterosexualidad, renunciaría a lo femenino, definiéndolo como su antonomasia, valida la homosocialidad como el estilo de relación más importante y promueve el persistente escrutinio por parte de los otros hombres; aprueba la homofobia y sostiene el sexismo y el heterosexismo (Kaufman, 1985; Kimmel, 1998; Olavarría y Parrini, 2000).

Principalmente desde la sociología y la antropología se plantea que el modelo anteriormente descrito presenta ciertas fisuras producto de los procesos de democratización acaecidos en las últimas décadas (Guasch, 2006). Asimismo, debido a la explicitación de la violencia física y simbólica que el sistema patriarcal ha ejercido hacia las mujeres y los agenciamientos por parte de colectivos sociales que buscan una reorganización de la estructura social (Kaufman, 1985, 1993, 1994, 2000).

Abarca (2002), afirmará que en la representación de la masculinidad de los varones heterosexuales presente en Chile, existe un modelo de relación entre los sexos al interior del cual conviven dos racionalidades: una tradicional, que enfatiza la noción de jerarquía y diferencia complementaria, y otra moderna, adscrita a nociones de igualdad, libertad y reflexividad. En efecto, existiría un modelo hegemónico de masculinidad crecientemente socavado por los efectos del proceso de globalización y los nuevos valores y prácticas que trae consigo, especialmente el nuevo rol asumido por las mujeres en el ámbito público.

En ese sentido, los principales ejes analíticos que han definido el estudio de las masculinidades en Chile han sido la paternidad, el trabajo, la violencia en el contexto intrafamiliar y social, el rol de 
jefatura familiar $y$ las diferencias generacionales entre hombres (Olavarría y Parrini, 2000; Valdés y Olavarría, 1998). Se discute en el estudio de las masculinidades Chilenas la vinculación entre las actividades productivas con la noción de una identidad masculina irreflexiva, en estrecha relación con un conjunto de expectativas y estereotipos asociados al género.

En términos socioculturales, este estudio se situó en la nortina región de Antofagasta, capital minera de Chile. En dicho contexto, investigaciones previas han planteado que la principal actividad productiva, en conjunto con normas rígidas en cuanto al género, promueven estereotipos de género asociados a un hombre proveedor, fuerte, reservado, competitivo, orgulloso, sexualizado, desconfiado y viril. En contraposición, se valora en las mujeres, recato, subordinación y sumisión, así como también se promueve el rol materno y actividades vinculadas al cuidado en el espacio doméstico (Barrientos y Silva, 2006).

Los elementos antes señalados favorecerían la reproducción de un modelo hegemónico de masculinidad androcéntrico, heterosexista y falogocentrado, basado en un sistema de jerarquías, constante comparación y competencia entre resistencia emocional y fortaleza física (Salinas y Barrientos, 2011). Lo anterior, reforzará los postulados de Connell (2003) en el sentido de que las características contextuales del trabajo, las circunstancias económicas y las estructuras de las organizaciones, influirían en la forma en que se configura la masculinidad.

Por tal motivo, el objetivo que guió esta investigación consistió en comprender el proceso de subjetivación de la masculinidad en hombres jóvenes en el norte de Chile, buscando dar respuesta a cómo significan y viven sus masculinidades aquellos jóvenes socializados en un escenario cultural heteropatriarcal caracterizado por investigaciones precedentes en la región. Asimismo, de qué forma se articulan emociones, mandatos culturales en torno al género y sus experiencias corporales en el entramado semiótico-material (Haraway, 1995) de la cultura minera del norte Chileno.

A nivel conceptual, se establecerá un distanciamiento a priori de la noción de identidad asociada a la masculinidad, la cual ha estado presente en la agenda sobre el estudio de las relaciones de género en las dos últimas décadas. Lo anterior, puesto que encapsula y rigidiza un proceso siempre inacabado y móvil como es la vivencia del género (Parrini, 2007).

De modo que la propuesta que sostiene este trabajo, entenderá entonces los mecanismos de subjetivación como el proceso de regulación de la subjetividad para todos los seres sociales (De Lauretis, 1989). Asimismo, la subjetividad como espacio simbólico supone agenciamientos frente al poder, aconteciendo posibilidades para la emancipación y un campo de lucha entre diferentes configuraciones de sujeto (Galaz, 2012). Emergerá así en la socialización de género una relación entre género, poder y subjetividad (Amigot, 2005; Butler, 1997; Pujal, 2003) de vital importancia para la investigación social en materia de relaciones de género.

Por otro lado, se incorpora un abordaje de las emociones desde el denominado "giro afectivo" en psicología social (Lara y Enciso Domínguez, 2013). Este enfoque permitirá complejizar el abordaje de las emociones en el estudio de la subjetividad, desde una perspectiva corporeizada, propuesta en este artículo. Esta comprensión pretende así aportar una comprensión "situada" de la afectividad en contraposición a enfoques en psicología social que estudian las emociones desde una perspectiva evolucionista como es el caso del trabajo de Barsalou (2008), el cual es denominado como "embodied-cognition emotion". 
MÉTODO

El modelo metodológico utilizado correspondió a "Mapas Corporales" (Silva, 2013). Este modelo se ubica en la tradición del paradigma comprensivo-interpretativo, y particularmente, en el enfoque biográfico.

Dicho modelo responde al propósito de contribuir a la generación de conocimientos sobre la experiencia biográfica del cuerpo en la intersección de epistemologías feministas, principalmente con base en los aportes de la epistemología de los "Conocimientos Situados" de Donna Haraway (1995) y la noción de "embodiment" o "corporeidad" (Butler, 1990; 1993), introduciendo así un viraje a la perspectiva biográfica tradicional. En su producción se articulan técnicas de recolección de información, análisis y criterios de validación de la investigación cualitativa (Silva, Barrientos, EspinozaTapia, 2013) ${ }^{1}$.

Los "Mapas Corporales" proponen una cartografía semiótico-material (Haraway, 1995) que articula las significaciones y sentidos del sí mismo como parte de un lenguaje entramado en la biografía y corporalidad de cada sujeto. Lo anterior, responde al interés de incorporar en los estudios biográficos la experiencia corporal como una persistente interrogante que atraviesa a la investigación social, puesto que en palabras de Foucault, es la carne la que encara resistencias e incógnitas por donde circula el poder social (Foucault, 1998).

En la elaboración de los mapas corporales participaron 47 jóvenes (23 hombres y 24 mujeres) de 15 a 23 años, pertenecientes a establecimientos educativos de enseñanza secundaria y universitaria, públicos y privados, de distintos niveles socioeconómicos. Sin

1. A fin de profundizar en el modelo metodológico se sugiere revisar: Silva, J., Barrientos, J. y Espinoza-Tapia, R. (2013). Un modelo metodológico para el estudio del embargo, a fin de responder a los objetivos propuestos para esta investigación se seleccionaron los mapas corporales de hombres. En particular, con la finalidad de ilustrar en profundidad la propuesta de análisis intertextual se desarrollará el análisis de un mapa corporal. El Mapa corporal seleccionado ha sido el de "Hombre Constelación".

Como criterios de inclusión para participar de la investigación se solicitó a los participantes: voluntad y disposición para trabajar en el proceso de reapropiación corporal y autonomía subjetiva a partir de la recuperación de eventos autobiográficos, Continuidad y sistematicidad para participar en todas las sesiones.

Desde el punto de vista ético, los objetivos de la investigación y la metodología de trabajo fue aprobada por el comité de bioética de la Universidad Católica del Norte. Por otro lado, se solicitó la firma de asentimiento y consentimiento informado para jóvenes, padres-madres y/o personas a cargo del cuidado personal de los/as participantes menores de 18 años.

La producción de información se organizó en 10 sesiones de trabajo de una hora y media de duración. La elaboración del mapa se estructuró en función de: conversaciones temáticas grupales, elaboración de líneas de vida y relatos autobiográficos. En este proceso se trabajó con nudos biográficos para recuperar eventos significativos, estimular procesos de reflexividad y textualización. Esta fase se caracterizó por su nivel de densidad simbólica, ya que se estimula una representación subjetiva del "Yo" sexogenerizado junto con auto-interpretaciones intertextuales de sus biografías corporales.

En la fase gráfica, se elaboró un esquema corporal sobre un papel en dimensiones reales que funcionó como plantilla donde se proyectó la iconografía de sus experiencias subjetivas y la 
reinscripción de narraciones sobre sus emociones y mandatos de género. Se trabajó bajo criterios de voluntad propia en la selección de eventos, dejando en libertad el uso de materiales, formas y colores.

El trabajo de elaboración del mapa corporal se realizó de forma individual a fin de favorecer la autoexploración. Lo anterior, ya que este modelo propone, en una primera etapa, que los lenguajes de la corporalidad permiten tomar conciencia de esa "encarnación" concreta, cotidiana, subjetiva y emocional del orden social a partir de un ejercicio de reflexividad. Además, este periodo significa descubrir el propio cuerpo en su materialidad: recorrer sus pliegues, texturas, formas y matices.

En ese sentido, la representación de procesos emocionales y de socialización de género mediante iconografía, textos, colores y dibujos, dan cuenta de elementos simbólicos nucleares en la experiencia del sujeto. Esta nuclearidad se sostiene en el concepto de "imagen corporal" (Guimón, 1999; Raich, 2000), puesto que cada persona posee a nivel intrapsíquico una imagen de sí mismo, que se activa y retroalimenta con la mirada de otros y los discursos socioculturales que le sostienen.

En el análisis interpretativo del material se articulan las siguientes tres dimensiones: Narrativa, Gráfica-Proyectiva e Interpretativa, dando cuenta de una comprensión intertextual, inspirada en los trabajos de Julia Kristeva (1967), Jacques Derrida (1971) y Roland Barthes (1987). Estos autores utilizan la intertextualidad para dar cuenta de los múltiples juegos de lenguaje presentes en la cultura. Roland Barthes, por ejemplo, plantea un ideal de textualidad donde abundan las redes que actúan entre sí, sin que ninguna pueda imponerse a las demás.

El modelo propone trabajar en dos momentos analíticos (ver figura $\mathrm{N}^{\circ} 1$ ):

FIGURA 1.

Ejemplo de matriz de análisis intertextual.
A. Tratamiento del corpus documental: A su vez, se compone de las siguientes etapas. 1. Reconocimiento de productos de valor simbólico del proceso autobiográfico junto con selección de microtextos significativos de acuerdo a los criterios de búsqueda o dimensiones a estudiar; 2. Organización de categorías de análisis; 3. Elaboración y organización de matrices analíticas, articuladas con interrogantes del investigador (en este caso, la subjetivación de la masculinidad); 4 . Contrapunto teórico; y finalmente, 5 . Integración y sistematización de microtextos y mapa corporal elaborando una red intertextual compuesta de color, forma, iconografía, textualidad y significados.

B. Proceso de interpretación, reinterpretación e intercambio entre participantes e investigadores: A su vez, se compone de las siguientes etapas. 1. Retroalimentación a los participantes sobre el proceso individual y grupal; 2. Reinterpretaciones, debate y contraste de propuestas de interpretación del material entre los participantes; 3. Co-construcción de un modelo de análisis-hallazgos emergente. 


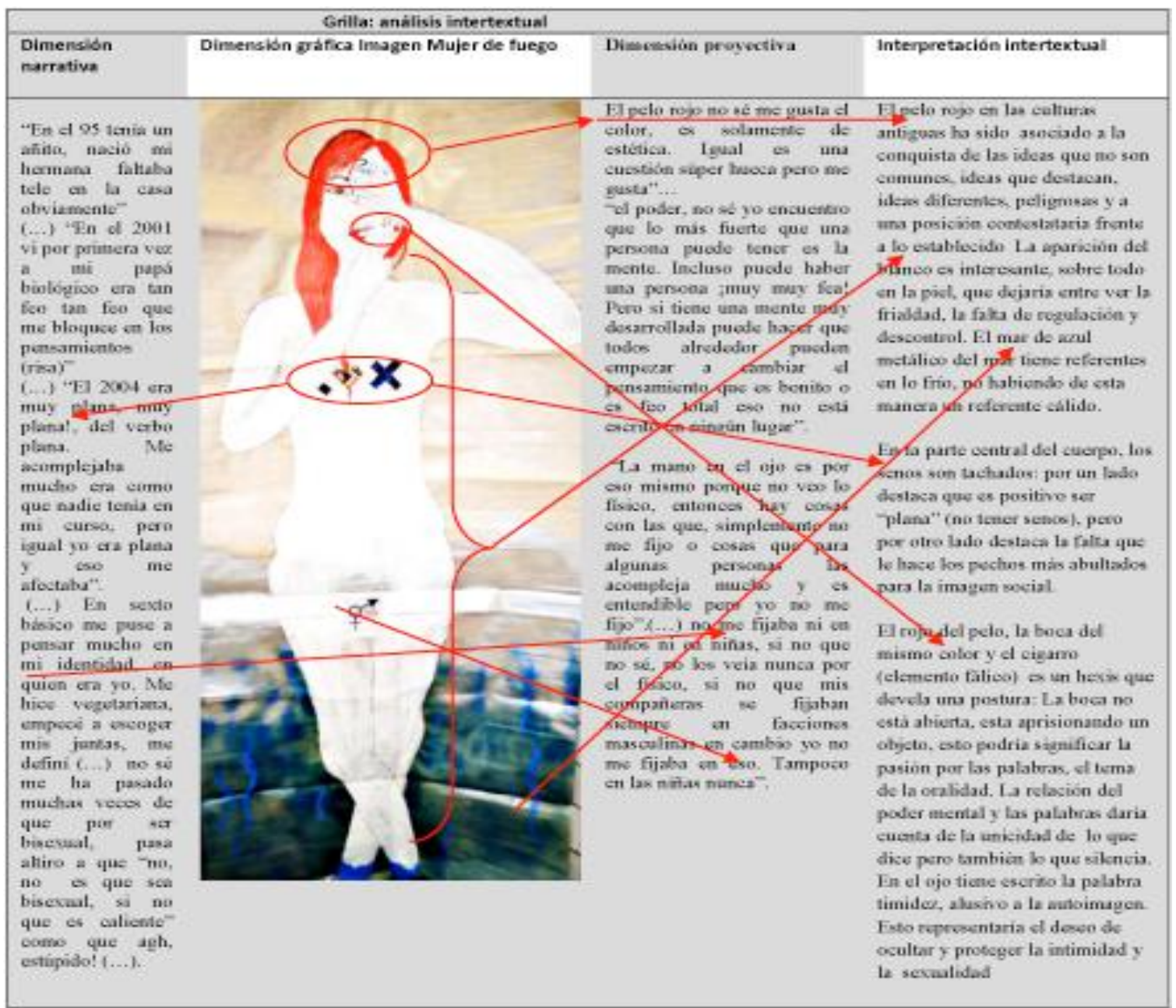

Fuente: Elaboración Propia

Resulta relevante destacar que el proceso de interpretación de los hallazgos, a la vez que la sistematización de la subjetivación de género, presente en el mapa corporal se articula en función de un proceso dialógico en todo momento con el/la participante. De modo que se desdibuja la lógica investigador-investigado durante el momento analítico puesto que, tanto el proceso de interpretación, como así también, la elaboración del material es coparticipativa. Lo anterior, supone la creación de manera conjunta del mapa corporal y sus interpretaciones, siendo una propuesta dialógica donde la reflexividad del participante, junto con la del grupo y el facilitador (investigador/a) se encuentran en constante dialogo y contrastación hasta la elaboración final del mapa corporal.

Finalmente, el investigador/a establecerá determinados análisis a fin de dar respuesta a sus preguntas de investigación y los objetivos trazados en el proyecto.

\section{RESULTADOS}

A continuación se presenta el análisis del mapa corporal de "Hombre Constelación"2 (ver figura 2). Este mapa fue seleccionado para ejemplificar procesos de subjetivación de la masculinidad de jóvenes socializados en el norte de Chile. 


\subsection{Dimensiones Narrativas y Gráfica / Proyectiva}

Joven 21 años, estudiante universitario, nivel socioeconómico medio. Universidad privada.

Se grafica un cuerpo erguido y de frente, demarcado en todo su contorno por una línea negra gruesa hecha con un pincel. A lo largo del dibujo, el sujeto nos indica una ruta a seguir para la lectura de su mapa. Esta es denominada "Ruta de la lujuria" e indica las zonas erógenas de su cuerpo mediante el dibujo caricaturizado de una serpiente gris. El recorrido supone ocho segmentos: boca, orejas, cuello, pecho, pies, zona interna del muslo, manos y la zona genital denominada como "meta".

FIGURA 2.

Hombre Constelación.

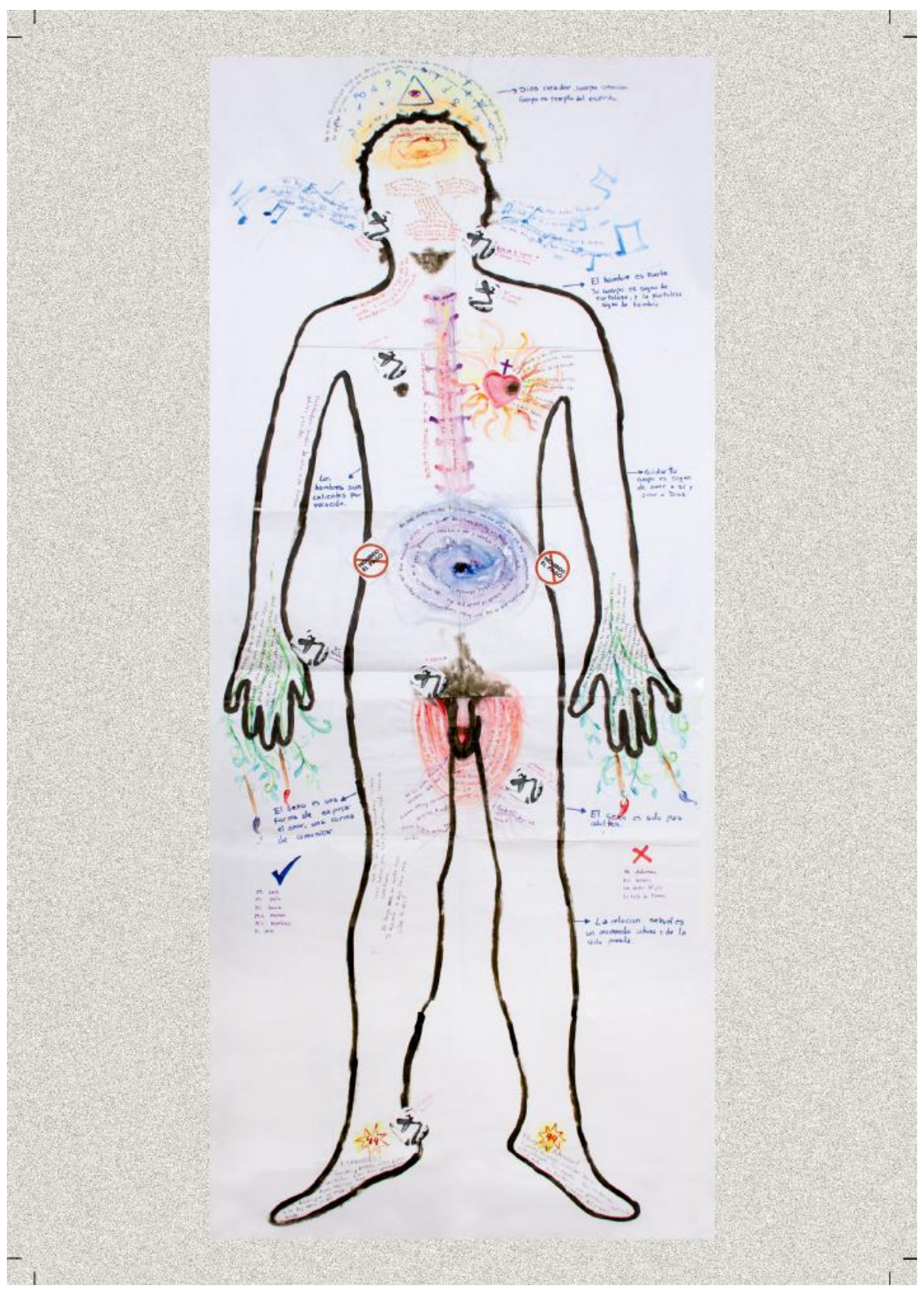


En la parte superior externa a la cabeza, justo en medio se encuentra dibujado el "Ojo de Horus" o también conocido como "ojo mágico". Alrededor de este se agregan signos de color azul, tales como: el símbolo griego "psiche" (alma), signos de interrogación y exclamación, símbolo griego de masculino, signos matemáticos, entre otros. Sobre estos está escrito: "No me mires. Escucha lo que tengo que decir. Soy una cabeza y nada más. No me hagas recordar que tengo cuerpo y siento. Yo analizo. Mi cabeza como una luz, flota sin origen ni destino ¿Por qué hacerme recordar que también soy carne y sangre viva?".

Al interior de la cabeza y a la altura de la frente, incorpora siluetas que simulan ser fantasmas, y sobre estas el texto: "Esta cabeza es como un libro abierto, una galaxia confusa, un caserón de fantasmas"

La boca o los labios no se encuentran dibujados al igual que el resto de los rasgos de la cara. En reemplazo de estos ha escrito acerca de ellos sobre los sitios donde deberían ir ubicados normalmente. Sobre la boca escribe: "Ruta de la lujuria: primera parada la boca" (...) Mira mi boca que besa, que no sonríe y que muerde. Déjame sentir tu boca en mi boca, pero no me hagas sonreír, podría espantar tu boca".

En el lugar de las cejas y los ojos consigna: "Déjame mirarte y mirarme. Es una maraña de ojos. Miro y escondo el fusil de mi mirada. Y bajo mis gruesas cejas me escondo. Te miro y quiero que 10 notes. Quiero que sientas mis ojos". En la nariz escribe: "Crece y se abalanza prominentemente, es mi herencia. Esa pequeña joroba, mi querida herencia".

Las orejas tampoco han sido dibujadas, sin embargo, a la altura de estas "Hombre Constelación" atraviesa la cabeza de un lado a otro con símbolos asociados a notas musicales y líneas curvas en azul que simbolizarían la reverberación del sonido. Sobre las orejas escribe: "Segunda parada: las orejas". "No hay mejor entrada que mi oído. Déjame oír... la música puede llenarlo todo. Si tu voz me llega, habrá llegado la mitad de ti a mi centro. Siempre escuchando. Quiero oír la música, tu voz, tus gestos, tus sonidos junto a mi".

La división entre el rostro y el cuello está dada solo por la barbilla, la cual es coloreada con marrón, simulando vello facial. Mismo color que el cabello dibujado en el contorno de la cabeza. Respecto a su cuello consigna: "Tercera parada: el cuello". "Me desentiendo... y bajas por mi cuello. $Y$ notas que lo noto, pero me desentiendo. $Y$ sabes que me gusta".

Cerca del hombro izquierdo, fuera del cuerpo señala: " $\rightarrow$ El hombre es fuerte. Su cuerpo es signo de fortaleza, y la fortaleza signo de hombría". A la altura del pecho dibuja columna, pezones, corazón y dos caricaturas asociadas a la serpiente que metaforiza "la ruta de la lujuria". En una de ellas indica: "Cuarta parada: el pecho". En el centro de esta zona se encuentra graficada la columna vertebral, utilizando amarillo, rosado y violeta. A lo largo del dibujo de la columna escribe: "Vertebra por vertebra. Torcido... desviado. Vertebra por vertebra, el dolor y la vergüenza”. Además, reitera escribiendo de forma vertical a la columna la siguiente frase: "Vertebra por vertebra".

En dicha área y sobre su pectoral izquierdo, dibuja un pezón y sobre este un corazón rojo con una cruz violeta clavada en la parte superior, representación del "Sagrado corazón de Jesús". Alrededor del corazón se encuentran dibujadas a modo aura líneas curvas amarillas, naranja y rojas, sugiriendo un corazón que destella luz. Hacia el costado izquierdo del corazón está escrito: "Dios delante y yo atrás. Sé que es mi camino. Sabes que a pesar de ser torcido, sé que me guarda cariño, 
como se lo guardo yo. $Y$ está encarnado no sólo en mi mente, se guarda también en el cuerpo".

En el centro del área abdominal se encuentra una leyenda escrita formando una espiral que sugiere una constelación en torno al ombligo. Utiliza colores celeste, violeta, gris, azul y negro para trazar dicha constelación. El ombligo simula un agujero negro. La leyenda dice: "No me mires ni me toques aquí. No me recuerdes que soy imperfecto. No descubras que no soy tan lindo como creías. No me toques aquí que tiemblo. No vaya a ser que descubras que soy un sobre alimentado. Que sigo siendo el gordo que fui. ¡No mires ni te fijes! Entonces vuelvo a ser y vuelvo a escuchar: guatón, gordo, chancho, vaca, morsa culiá!"

A la altura de la cintura e inicio de las caderas ubica en ambos costados símbolos que señalan: "prohibido el paso". Utiliza iconografía usada en el tránsito urbano, simbolizando restricción para el acceso.

Los brazos se encuentran dibujados de forma semi-rígida a los costados del cuerpo. Escribe sobre ellos: "Debiluchos, brazos de niño, no de hombre. Débiles y caídos". Al costado externo de su brazo izquierdo incorpora la frase: "Cuidar tu cuerpo es signo de amor a sí y amor a Dios". Entre el costado interno del brazo derecho y la costilla está escrito: "Los hombres son calientes por vocación".

Las manos están dibujadas con dedos definidos y algunos semi-abiertos. Desde los dedos de ambas manos se desprenden ramificaciones en verde claro, verde oscuro y azul, dibujando pequeñas hojas que se proyectan desde las manos. Asimismo, en las terminaciones, ramificaciones y dedos. Dibuja dos pinceles saliendo de cada mano. Uno con pelos rojo y el otro azul.
Se inscribe la siguiente leyenda: "Séptima parada: Las Manos". En la mano derecha: "Mis manos para pintar, para tocar, para escribir, para seguir pintando, para defenderme, para crear, para pedir, para orar, para excitarte, para tocar, para acariciar ¡Por Dios, cuánto cuesta acariciar!". En la mano izquierda: "Mis muy queridas, incluso tu mi izquierda algo inútil. Tantos buenos momentos. Pandoras de formas, de líneas y de letras. Poco menos de caricias, de golpes menos aún. Un poco de trabajo, de abrirse al otro. Mis muy queridas mellizas pintadoras, escritoras, manoseadoras, seductoras, masturbadoras, tocadoras, la pasamos bien. Mis muy queridas, pacíficas, curiosa, pecadoras!"

En el área genital el pene es dibujado con borde negro y coloreado en tonalidades rojizas, el vello púbico en color café, en la zona interior de las piernas y alrededor del pene se grafica un óvalo en tonalidades rojizas donde se encuentran las siguientes inscripciones: "Meta". "Se siente como un atributo importante. Como una consideración que da orgullo tener. Parte de mí, fuera de mí. Complaciente y complacido, se deja querer. No se complica frente al resto. Sabe qué es 10 que tiene que hacer. Dios 10 guarde ¡Amén!”.

Bajo la zona interna de las piernas se encuentran líneas violeta semi curvas las cuales sugieren estrías en la piel. Sobre estas líneas se encuentra escrito en la misma tonalidad: "Sexta parada: la zona interna del muslo" "No las mires tanto doctora... solo son estrías. No soy fenómeno de circo. A cualquiera le pasa. Nunca haz... jEntonces de mirar!".

Las piernas están dibujadas de forma recta, levemente separadas. Sobre su pierna derecha y de forma vertical señala: "¿Qué les ves, qué les encuentras? Conozco cosas buenas, pero este par de piernas nada tiene de espectacular. No 
tengo nada en contra suyo. Te dejo mirar... Te dejo tocar, pero ¿qué le ves?". Al costado externo de la pierna derecha se encuentra escrito en azul: "El sexo es una forma de expresar el amor, una forma de comunicar." Al costado externo de su pierna izquierda en azul: "El sexo es solo para adultos." "La relación sexual es un momento íntimo y de la vida privada."

A ambos costados de las piernas establece dos listados en referencia a las partes de su cuerpo que resultan de su agrado y las que no. Las primeras marcadas con una tilde azul de aprobación, justo al costado inferior de la pierna derecha, identifica: "Mi cara, $\mathrm{Mi}$ pelo, Mi boca, Mis manos, Mis hombros, Mi pene". Las segundas, al costado inferior de la pierna izquierda, marcadas por una cruz roja, rechaza: "Mi abdomen, Mis brazos, Los dedos del pie, La falta de trasero".

Los pies están dibujados de forma que apuntan hacia afuera. A la altura de ambos tobillos se encuentra un signo que impresiona como el estallido de una estrella en tonalidad amarilla y letras rojas. En su interior inscribe el número "44", haciendo referencia a su talla de calzado. Sobre los pies inscribe la siguiente frase: "Quinta parada: los pies". Sobre el pie

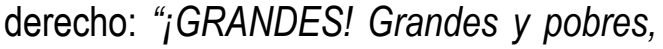
nadie quiere recibirlos. Viven tan apretaditos. Nunca hay casa tan amplia que los reciba. Y si la hay, nunca es del gusto". Sobre el Pie izquierdo: "Pues se adecuan! Gigantes traviesos, no pueden dormir a la intemperie. Tan torpes... Tan arrítmicos. $Y$ todas las fantasías que generan! ¿Cuál es la proporción del número 44?".

\subsection{Dimensión interpretativa: Análisis intertextual}

"Hombre Constelación" subjetiva su masculinidad a través de tres elementos predominantes en su mapa corporal. En primer lugar, mediante iconografías asociadas a su espiritualidad, y asimismo, a la existencia de un mundo interno el cual lo vincula a prácticas artísticas e intelectuales que destaca del sí mismo. En segundo lugar, se logra identificar la presencia de discursos normalizadores provenientes desde la familia y su entorno respecto a la masculinidad. Estos se inscriben en azul y destacan simbólicamente en el mapa, siendo remarcados por una flecha fuera del contorno del cuerpo. En tercer lugar, se identifican mandatos culturales asociados a la masculinidad y la sexualidad. Estos se sitúan en lugares específicos del cuerpo. "Hombre Constelación" carga de emociones y ámbitos de significación segmentos de su cuerpo, los cuales se vinculan con su socialización de género y dan sentido a su experiencia corporal.

\subsubsection{Segmento superior del mapa: Cabeza-Rostro}

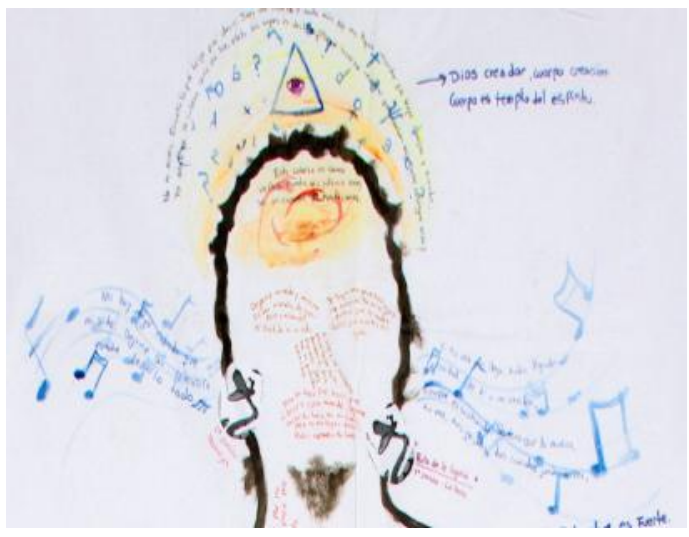

Se logra apreciar una valoración de lo intelectual y/o racional por sobre lo sensitivo presente en otras zonas del cuerpo. Si bien se destacan graficas que sugieren una orientación hacia actividades sensibles como las artes y la música, pareciera que el mundo de las ideas constituiría un elemento central en la subjetivación de "Hombre Constelación". Asimismo, existe un desplazamiento de la corporeidad a un segundo plano. Lo racional es significado como sublime, estableciendo una categorización entre lo cognitivo versus lo sensitivo y corpóreo. 
"No me mires. Escucha lo que tengo que decir. Soy una cabeza y nada más. No me hagas recordar que tengo cuerpo y siento. Yo analizo. Mi cabeza como una luz, flota sin origen ni destino ¿Por qué hacerme recordar que también soy carne $y$ sangre viva?"

El "Ojo de Horus", dibujado sobre la cabeza, simboliza en la cultura egipcia la energía del pensamiento. Estaría relacionado con el desarrollo o evolución hacia la perfección y la estabilidad, tanto espiritual, como intelectual. Los símbolos ubicados alrededor de este representarían el mundo de las ideas, dando sentido a un atributo valorado por la masculinidad hegemónica como es la racionalidad y la inteligencia. El color azul con el que han sido representados estos símbolos se asociaría a lo divino y también a la frialdad afectiva (Heller, 2008).

El rostro carece de facciones dibujadas, en su lugar, se consignan narrativas que describen la vivencia y sensaciones atribuidas a dichos órganos. La boca constituiría una zona erógena identificada como el inicio de la denominada "Ruta de la lujuria", la cual podría identificarse como el primer contacto con otro. Sin embargo, se expresa una tensión en torno a la sonrisa, puesto que manifiesta: "(...) Déjame sentir tu boca en mi boca, pero no me hagas sonreír, podría espantar tu boca". Lo anterior, se puede interpretar como un acto de disconformidad hacia el sí mismo, a la vez que un mecanismo de protección frente al rechazo.

El área de ojos y cejas es significada como un lugar para la comunicación. Los ojos representan una función de seducción y contacto con el mundo. Las cejas constituyen una suerte de guarida desde donde el sujeto puede interpelar al otro con la mirada y hacer manifiesta su presencia: "(...) Miro y escondo el fusil de mi mirada. $Y$ bajo mis gruesas cejas me escondo. Te miro y quiero que lo notes. Quiero que sientas mis ojos".

La nariz le contacta con la genética familiar, es significada por el sujeto como parte de una herencia que le otorga sentido de pertenencia. Las orejas son identificadas como la "segunda parada de la ruta de la lujuria". Un espacio de conexión sensitivo con el mundo externo e interno puesto que se vincula a su afición por las disciplinas artísticas. Asimismo, cobra sentido en su experiencia corporal la audición como un vehículo para establecer contacto con los otros y ser seducido. Lo anterior, podría relacionarse con la relevancia del mundo de las ideas versus la dimensión material de la experiencia corporal.

El cuello es significado como la "tercera parada". "Hombre Constelación" le otorga una connotación erótica, siendo una vía de acceso al placer sexual. "Me desentiendo... $y$ bajas por mi cuello. $Y$ notas que lo noto, pero me desentiendo. $Y$ sabes que me gusta".

\subsubsection{Segmento medio del mapa: Torso-Abdomen}

Existen tres elementos iconográficos que destacan en este segmento del mapa: La columna vertebral, el sagrado corazón de Jesús y el abdomen simbolizado como una constelación. Estos se articulan de forma que generan una tensión en la subjetivación de la masculinidad de "Hombre Constelación".

La zona de los hombros simboliza en la cultura popular la noción de carga. "Hombre Constelación" consigna en su mapa el siguiente mandato de género sobre sus hombros: "El hombre es fuerte. Su cuerpo es signo de fortaleza, y la fortaleza signo de hombría". De modo que el adagio cultural entorno a construirse hombre y masculino es vivido desde una metáfora de pesadumbre y es asociado al imperativo de la fortaleza, tanto física como afectiva. 


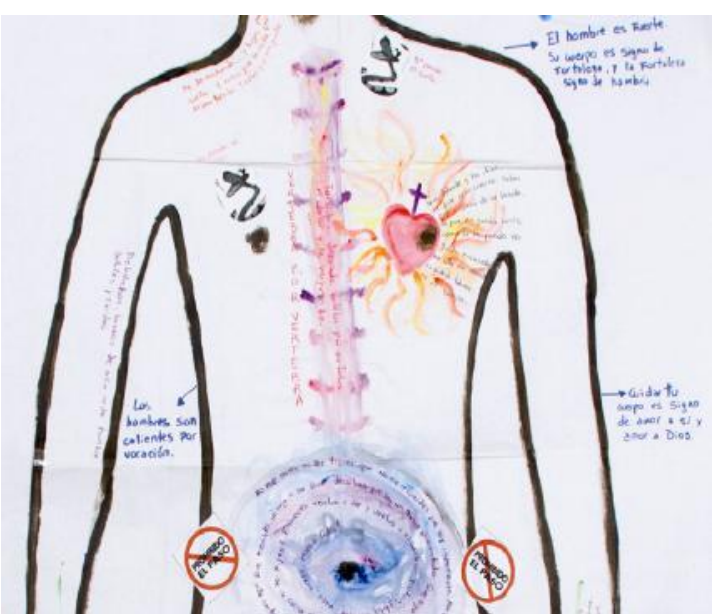

La "cuarta parada de la ruta de la lujuria", el pecho, supone una tensión particular debido a que es reconocida por "Hombre Constelación" como una zona erógena y a la vez lugar de espiritualidad vinculada a la religión católica. Se configura así una relación entre placer y un tipo de religiosidad que tensiona la vivencia de dicho placer sexual.

Lo anterior, debido a que la iconografía del "sagrado corazón de Jesús" para el cristianismo representa un acto litúrgico que refiere a fuego, sangre y amor divino, vinculado a la pasión de Cristo (Camacho y Guzmán, 2006). El corazón graficado posee una cruz violeta que le atraviesa por la mitad. Desde esta misma perspectiva, el color violeta simboliza para el cristianismo penitencia, recogimiento espiritual y una carga que se llevaría simbólicamente a través de la devoción (Camacho y Guzmán, 2006).

La columna vertebral ha sido trazada con tonalidades que dan su forma (amarillo, rosado y violeta). Esta estructura simboliza aquello que da sustento y mantiene erguido el cuerpo. Como contrapunto "Hombre Constelación" refiere: "Vertebra por vertebra. Torcido... desviado. Vertebra por vertebra, el dolor y la vergüenza". La reiteración de la frase "Vertebra por vertebra" sugiere un conflicto metaforizado en la figura del "árbol torcido", dando la sensación que en su proyecto de masculinidad no logró incorporarse a determinado orden normativo, subjetivándose como hombre abyecto.

La parte inferior de la columna se une a una suerte de constelación trazada en tonalidades celeste, violeta, gris, azul y negro. Dicha constelación simboliza el abdomen y es significada en el discurso como una zona de su cuerpo rechazada y en conflicto. Esto se confirma con la incorporación de iconografía que explicita "prohibido el paso", regulando así el acceso de otros a esta zona de su cuerpo en conflicto.

Desde una interpretación de género, el rechazo hacia aspectos de la corporeidad tales como la gordura se instala en la cotidianeidad de los sujetos como un mandato cultural. Este rechazo se fundamentaría en la exigencia de cánones de belleza contemporáneos y creencias en torno a la salud física que atribuyen a la gordura fealdad y enfermedad. Cualquier indicador asociado a la gordura es rechazado por "Hombre Constelación" puesto que le remite a experiencias rechazo $\mathrm{e}$ incluso violencia verbal en sus interacciones sociales. Pareciera que este malestar se instala tempranamente en su biografía.

"No me mires ni me toques aquí. No me recuerdes que soy imperfecto. No descubras que no soy tan lindo como creías. No me toques aquí que tiemblo. No vaya a ser que descubras que soy un sobre alimentado. Que sigo siendo el gordo que fui. ¡No mires ni te fijes! Entonces vuelvo a ser y vuelvo a escuchar: guatón, gordo, chancho, vaca, morsa culiá! 3"

La constelación representada en el abdomen adquiere centralidad en el mapa corporal. Sugiere una huella subjetiva que

\footnotetext{
3. Estas denominaciones injuriantes se refieren al uso idiomático en su cultura para dar cuenta del exceso de peso corporal.
} 
incorpora inseguridad, inconformidad con su corporalidad, y por tanto, una autoimagen deteriorada. En ese sentido, destaca el discurso de rechazo y vivencia de una alteridad producto del estigma social que supuso el sobrepeso en su subjetivación. "Hombre Constelación" revive los insultos de experiencias pasadas y los integra en la significación de la vivencia de su corporeidad en el presente como elemento fundacional de su imagen social.

En relación a los colores utilizados para representar la constelación, el violeta simbolizaría en la cultura andina grandes sufrimientos, experiencias 0 eventos nefastos (Camacho y Guzmán, 2006). El gris representaría la crueldad recibida por parte de los otros mediante la desacreditación y el insulto, asimismo, experiencias de sufrimiento psíquico (Heller, 2008).

El discurso de "Hombre Constelación" posee una interfaz entre el pasado y el presente, reconstruyendo eventos del pasado en su vivencia actual. En ese sentido, el "hoyo negro" que sitúa en medio del abdomen, simulando un ombligo, simbolizaría un proceso inconcluso que representa lo infinito, como así también, lo rechazado de sí mismo. Lo anterior, se relaciona con su énfasis en la idea de "vertebras desviadas" que estructuran un proyecto de masculinidad en los márgenes.

En su zona costal derecha "Hombre Constelación" registra en azul "Los hombres son calientes por vocación". Este mandato socializador de la masculinidad presente en el discurso posee una doble significación y función. Por un lado, una sexualidad naturalizada como parte de un sistema de prestigio de la masculinidad hegemónica. Por otro lado, la vinculación simbólica de la zona costal en la religión católica con la génesis de la vida, a la vez que un mecanismo de poder sobre lo femenino. Con relación a los brazos, la disminuida fuerza física y un debilitado desarrollo de musculatura estaría asociado a falta de vigor y constituiría para el sujeto rasgos de debilidad.

\subsubsection{Segmento inferior del mapa: área genital, manos y pies}

La genitalidad en la subjetivación de las masculinidades posee una fuerte carga simbólica. De modo que la forma en que es graficado el pene supone la asignación de estatus en diversas culturas. "Hombre Constelación" utiliza su pene como símbolo de estatus, asimismo, lo vincula al tamaño de sus pies, asignándole fortaleza a la construcción social de su virilidad. Lo anterior, tendría una funcionalidad en la experiencia subjetiva de "hombre Constelación" puesto que entrega prestigio $y$ seguridad a una masculinidad no competitiva en otros aspectos de la vida social.

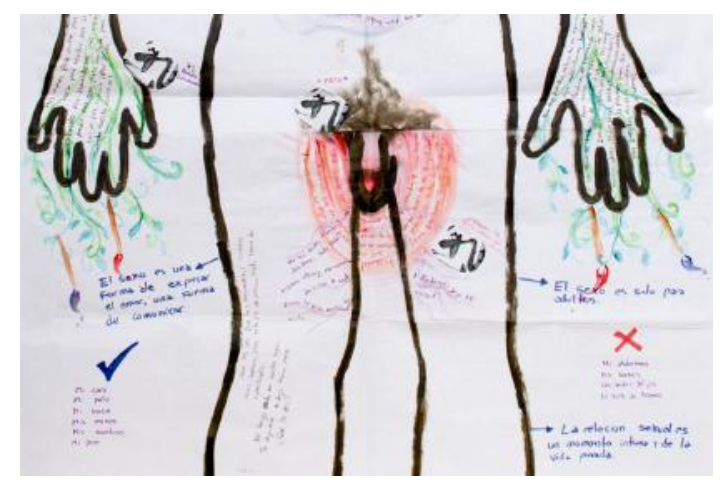

Las manos representan el contacto con una sensibilidad artística y su apertura hacia actividades creativas. Su sensibilidad se manifiesta mediante dibujos de hojas verdes que se proyectan desde las manos y rebasan la punta de los dedos. La elección del color y símbolos, refieren a germinación de la naturaleza. Además, representan el contacto con los otros en lo afectivo, eróticosexual, como así también, el autoerotismo (Camacho y Guzmán, 2006; Heller, 2008).

"Hombre Constelación" integra su dimensión sensitiva con su vivencia del deseo en la significación que otorga a sus manos. Estas le conectan con diversas experiencias a partir de la dicotomía: artes 
(permitido) versus sexualidad (restringido), tensionando la vivencia del deseo. Lo anterior, sugiere que el deseo y el sexo han sido incorporados en su socialización como algo pecaminoso: "(...) por Dios cuánto cuesta acariciarte". Así, cuando emerge el placer producido por el contacto con otro, "Hombre Constelación" se autoimpone limitaciones desde una normatividad religiosa y conservadora.

La talla de calzado " $\mathrm{N}^{\circ} 44^{\text {" que señala en }}$ sus pies entrega protagonismo a dicha característica física. Según Bourdieu (2000) los pies grandes han sido culturalmente vinculados en las sociedades occidentales a la masculinidad y la virilidad. En ese sentido, "Hombre Constelación" destaca dicho atributo como predicción de su potencia sexual. No obstante, la tensión entre el deseo y la normatividad moral y social genera en "Hombre Constelación" una atribución de la vida sexual a la adultez, existiendo una romantización e idealización de la sexualidad como forma de contacto con la pareja sexual. Lo anterior, asimismo, se relacionaría con su orientación hacia su mundo interno, predominando las emociones por sobre el placer en el contacto interpersonal.

\section{DISCUSIÓN}

El objetivo de la presente investigación consistió en comprender el proceso de subjetivación de la masculinidad en hombres jóvenes en el norte de Chile. Dicha comprensión supuso el abordaje de una perspectiva corporeizada y de género a sus emociones, mandatos de género $y$ experiencia corporal. Todas estas imbricadas en la forma de vivir y representar simbólicamente en un entramado semióticomaterial la masculinidad. Esta aproximación, Como señala Clifford Geertz (1987), será un proceso siempre incompleto, por tanto, una aproximación también incompleta al mundo simbólico de los jóvenes y sus cuerpos sexogenerizados.
A fin de profundizar el análisis intertextual de la presente la investigación se desarrolló en este artículo exclusivamente el caso de "Hombre Constelación". En ese sentido, el modelo metodológico de "Mapas Corporales" ha permitido identificar de qué forma jóvenes varones son interpelados en la subjetivación de su masculinidad por parte de los discursos y prácticas presentes en la cultura dominante, como así también, es posible identificar ciertos puntos de fuga, en tanto, procesos de reflexividad que ellos podrían hacer al modelo hegemónico propio de la cultura en que éstos se insertan. Dicho modelo se sostiene en la reproducción de mandatos de género tradicionales promovidos por un paradigma patriarcal, heterosexista y falogocentrado.

En el caso de "Hombre Constelación" se logra identificar la presencia de un discurso religioso como parte fundamental de la subjetivación de su masculinidad. En algunas áreas del cuerpo se consignan relatos vinculados a la vivencia corporal desde un lugar de abyección y alteridad ["Torcido... desviado" (...) "Vertebra por vertebra" (...) "El dolor y la vergüenza"]. Esto supone tensiones y malestar en la experiencia subjetiva y corpórea.

La zona de especial tensión y conflicto corresponde al torso (pectoral y abdomen) puesto que aquí se grafica el "sagrado corazón de Jesús", junto a la columna vertebral, como simbolización del sí mismo. Tanto la connotación de columna "torcida", como la constelación presente en su abdomen (que consigna formas injuriantes de interpelación que ha vivido en su experiencia biográfica), permiten identificar su anhelo de inclusión social, y asimismo, afectos negativos y rechazo hacia su corporalidad. Esto sugiere la presencia de malestar y sentimientos de inadecuación en el curso desde la juventud a la adultez de "Hombre Constelación". 
A estos elementos en conflicto, "Hombre Constelación", incorpora el rechazo por partes específicas de su cuerpo y una vivencia de gordura que han marcado la biografía. En ese sentido, las agresiones y el rechazo le han hecho subjetivarse desde una masculinidad débil, inadecuada y poco competitiva. Su vivencia corporal no supone una experiencia placentera. Esta tensión logra su máxima visibilidad cuando verbaliza y construye un relato en torno a las significaciones del sagrado corazón ubicado en el pecho. Esta iconografía le otorgaría estabilidad frente a un mundo adverso, a la vez que le adscribe en un orden moral de normatividad y hegemonía cultural.

"Hombre Constelación" valora el mundo de las ideas, exaltando características como la racionalidad 0 la intelectualidad que simboliza en su mapa corporal como uno de sus principales atributos. Este atributo vinculado a formas de masculinidad hegemónica facilitaría el desarrollo de una imagen social competitiva entre sus pares. Lo anterior, será utilizado por "Hombre Constelación" como una forma de enfrentar la inexistencia de atributos físicos valorados en su cultura tales como el vigor y la fuerza. Asimismo, mandatos culturales que le sujetan y hacen subjetivarse en oposición a la belleza y/o la delgadez.

Con relación a la socialización de género es posible identificar mandatos de una masculinidad hegemónica incorporados en su subjetivación sin mayor cuestionamiento. No se aprecia una crisis debido a la coexistencia de discursos tradicionales, propios de una masculinidad heteronormativa, y su conexión con aspectos sensibles del mundo (su valoración por las artes y el despliegue de las emociones). Tampoco, una posición reflexiva respecto al discurso religioso transmitido desde la familia de origen, el cual si bien le ha incorporado en una normatividad moral y social, también ha generado sujeciones y vivencias desde una posición de alteridad.
Respecto a su performance de género, existiría una subjetivación marcada por la abyección. El exceso de peso cobra relevancia en la narrativa y reflexividad autobiográfica. No obstante, la masculinidad hegemónica en su contexto sociocultural atribuye importancia a características físicas como la fuerza o la musculatura, de allí que su experiencia de alteridad reverbera en la subjetivación de su masculinidad, posicionándolo como un sujeto débil, rechazado y no competitivo. La compensación de su imagen deteriorada emerge a través de su significación del mundo de las ideas y su intelectualidad como elemento constitutivo de su autoimagen. Asimismo, la utilización del valor simbólico y el prestigio atribuido al vigor y potencia sexual.

El modelo de masculinidad de "Hombre Constelación" esta dado por una compensación entre el rechazo hacia una corporeidad disminuida y la exaltación de atributos propios de una masculinidad heteronormativa (racionalidad y virilidad producto del tamaño de su pene), legitimando así el modelo de masculinidad hegemónica presente en su entorno sociocultural.

Lo anterior, sugiere que no se identifica en "Hombre Constelación" una apertura hacia un modelo transformador en cuanto a las relaciones de género. De allí que esta propuesta analítica busque aportar hacia una comprensión de las formas en que se subjetiva la masculinidad por parte de jóvenes en el norte de Chile, la incorporación de las emociones en la subjetividad desde una experiencia corporeizada, y asimismo, los desafíos para el establecimiento de relaciones basadas en la equidad de género e igualdad de derechos.

En síntesis, es pertinente explicitar que los procesos de marginalización y exclusión a los que son expuestos determinados cuerpos, sujetos y prácticas, en el 
entramado de la gubernamentalidad neoliberal de género, requiere favorecer procesos de reflexividad que estimulen el cuestionamiento de los ejes de discriminación que no solo afectan a los sujetos posicionados tradicionalmente en los márgenes (mujeres, gay y lesbianas, migrantes, personas con diversidad funcional). Esto supone explicitar que inclusive aquellos hombres situados aparentemente en posiciones de privilegio igualmente son impugnados, exigidos y desconfirmados en sus masculinidades por un aparato ideológico avasallador al que pareciera imposible satisfacer.

\section{REFERENCIAS}

Abarca, H. (2002). Discontinuidades en el modelo hegemónico de masculinidad. Disponible en: http://www.hombresigualdad.com/disco ntinuidades.htm Recuperado el 04 de noviembre del 2013.

Amigot, P. (2005). Relaciones de poder, espacio subjetivo y prácticas de libertad: Análisis genealógico de un proceso de transformación de género. Tesis doctoral Universitat Autònoma de Barcelona, 2005. Consultada el 28 de septiembre de 2014 de http://www.tesisenred.net/TDX0313106-165412

Badinter, E. (1993). XY, la identidad masculina. Barcelona: Alianza.

Barsalou, L. W. (2008). Grounded Cognition. Annual Review of Psychology, Vol.59, Pp. 617-645.

Barrientos, J. y Silva, J. (2006). De la restricción a la equidad. Estudio cualitativo sobre el comportamiento sexual en la región de Antofagasta. Antofagasta-Chile: Ed. Universidad católica del Norte.

Barthes, R. (1987). El susurro del lenguaje. Más allá de la palabra y la escritura. Barcelona: Paidós.

Bourdieu, P. (2000). La dominación masculina. Barcelona: Anagrama.

Butler, J. (1990). El género en disputa. El feminismo y la subversión de la identidad. México: Paidós. (2001)

Butler, J. (1993). Cuerpos que importan. Sobre los límites materiales $y$ discursivos del sexo. Buenos Aires: Paidós (2002)

Butler, J. (1997). The psychic life of power: Theories in subjection. Stanford: Stanford University Press.

Camacho, H. y Guzmán, C. (2006). Los colores: símbolos rituales. Siglo XIX, Reunión anual de etnología. Anales de la reunión anual de etnología. La Paz: Museo nacional de etnografía y folklore. MUSEF. 
Connell, R. (1987). Gender and Power: Society, the Person and Sexual Politics. Cambridge: Polity Press.

Connell, R. (1995). Masculinities. UK: Polity Press.

Connell, R. (2003). Masculinidades. México: PUEG. Universidad Nacional Autónoma de México. Programa Universitario de Estudios de Género.

De Lauretis, T. (1989). Technologies of gender. Essays on Theory, Film and fiction. Londres: Macmillan

Derrida, J. (1971). De la gramatología. Buenos Aires: Siglo XXI.

Foucault, M. (1998). Vigilar y Castigar. Madrid: Siglo XXI. 27ava Edición.

Galaz, K. (2012). El señuelo de la integración: Los procesos de diferenciación, subjetivación y subalternización en los dispositivos educativos para las mujeres inmigradas. Revista iberoamericana de evaluación educativa. Vol.6 N¹.

Geertz, C. (1987). La Interpretación de las culturas. Barcelona: Gedisa.

Gilmore, D. (1994). Hacerse Hombre. Concepciones culturales de la masculinidad. Barcelona: Paidós.

Guasch, O. (2006). Héroes, científicos, heterosexuales y gays. Los varones en perspectiva de género. Barcelona: Bellaterra.

Guimón, J. (1999). Los lugares del cuerpo. Barcelona. Paidós.

Haraway, (1995). Ciencia, cyborgs y mujeres. La reinvención de la naturaleza. Madrid: Cátedra (1997).

Heller, E. (2008). Psicología del Color. Cómo actúan los colores sobre sentimientos y razón. Barcelona: Editorial Gustavo Gili.S.L.

Kaufman, M. (1985). The Construction of Masculinity and the Triad of Men's Violence. En Kaufman, M.(ed.) Beyond Patriarchy: Essays by Men on Pleasure, Power and Change. Toronto: Oxford University Press, 1985. Reeditado por O'Toole, L \& Schiffman,
J. Gender Violence. Nueva York: NY University Press, (1997).

Kaufman, M. (1993). Cracking the Armour: Power, Pain and the Lives of Men. Toronto: Viking Canada.

Kaufman, M. (1994). Men, Feminism, and Men's Contradictory Experiences of Power. En, Brod, H. \& Kaufman, M.(eds.). Theorizing Masculinities, Thousand Oaks, CA: Sage Publications.

Kaufman, M. (2000). The Seven P's of Men's Violence. Disponible en www.michaelkaufman.com

Recuperado el 17 de Marzo del 2013.

Kimmel, M. (1998). Desarrollo (de género) del subdesarrollo (de género). La producción simultánea de masculinidades hegemónicas y dependientes en Europa y Estados Unidos. En Valdes, T. y Olavarría, J. (Eds.). (1998). Masculinidades $y$ equidad de género en América Latina. UNFPA: FLACSO-CHILE.

Kristeva, J. (1967). Le mot, le dialogue, et le roman. Critique, 239 (1969). Semeiotike. Recherches pour une sémanalyse. Paris.

Lamas, M. (1996). El género, la construcción cultural de la diferencia sexual. México: Porrúa.

Lagarde, M. (1996). Género y Feminismo. Desarrollo humano y Democracia. Madrid: Horas y Horas.

Lara, A. y Enciso Domínguez, G. (2013). El giro afectivo: The affective turn. Athenea Digital. Vol.13(3): 101-119 (noviembre 2013).

Llamas, R. (1998). Teoría torcida. Prejuicios $y$ discursos en torno a la "homosexualidad". Madrid: Siglo XXI.

Olavarría, A. y Parrini, R. (2000). Masculinidad/es. Identidad, sexualidad y familia. Chile: FLACSO.

Parrini, R. (2007). Panópticos y laberintos: subjetivación, deseo y corporalidad en una cárcel de hombres. México D.F.: Colegio de México. Centro de estudios sociológicos.

Programa 
interdisciplinario de estudios de la Mujer.

Pujal, M. (2003). La tarea crítica: Interconexiones entre lenguaje, deseo y subjetividad. A partir del construccionismo social. Política $y$ Sociedad, Vol.40, N.1. Pp.129-158. Madrid.

Raich, M. (2000). Imagen corporal: conocer y valorar el propio cuerpo. Madrid: Pirámide.

Rubin, G. (1975). El tráfico de mujeres: notas sobre la 'economía política' del sexo. En Lamas, M. (1996). El género: la construcción cultural de la diferencia sexual. México: Universidad Nacional Autónoma de México-Programa Universitario de Estudios de Género/M.Á. Porrúa.

Salinas, P. y Barrientos, J. (2011). Los discursos de las garzonas en las salas de cerveza del norte de Chile: Género y discriminación. Polis, Vol.10, N.29. Pp.433-460. Santiago-Chile: Universidad Bolivariana.

Silva, J. (2013). Grafías del cuerpo, discursos y sujeciones corporales. En Silva, J. y Méndez, L. (eds.) (2013). Cuerpos y metáforas. Estudio de los significados culturales del cuerpo y las sexualidades juveniles. AntofagastaChile: EMELNOR/CONICYT.

Silva, J., Barrientos, J. y Espinoza-Tapia, R. (2013). Un modelo metodológico para el estudio del cuerpo en investigaciones biográficas: Los mapas Corporales. Alpha N.37. Pp.163-182. ISSN 0718-2201.

http://dx.doi.org/10.4067/S071822012013000200012

Valdés, T. y Olavarría, J. (1998). Masculinidades y equidad de género en América Latina. Santiago, Chile: FLACSO. 